\title{
Treatment of malignant pleural mesothelioma by fibroblast activation protein-specific re-directed T cells
}

Petra C Schuberth ${ }^{1}$, Christian Hagedorn ${ }^{1}$, Shawn M Jensen², Pratiksha Gulati ${ }^{1}$, Maries van den Broek ${ }^{1}$ Axel Mischo ${ }^{1}$, Alex Soltermann ${ }^{3}$, Astrid Jüngel ${ }^{4}$, Osiris Marroquin Belaunzaran' ${ }^{1}$, Rolf Stahel', Christoph Renner ${ }^{1,5+}$ and Ulf Petrausch ${ }^{5^{*}+}$

\begin{abstract}
Introduction: Malignant pleural mesothelioma (MPM) is an incurable malignant disease, which results from chronic exposition to asbestos in at least 70\% of the cases. Fibroblast activation protein (FAP) is predominantly expressed on the surface of reactive tumor-associated fibroblasts as well as on particular cancer types. Because of its expression on the cell surface, FAP is an attractive target for adoptive T cell therapy. T cells can be re-directed by retroviral transfer of chimeric antigen receptors (CAR) against tumor-associated antigens (TAA) and therefore represent a therapeutic strategy of adoptive immunotherapy.
\end{abstract}

Methods: To evaluate FAP expression immunohistochemistry was performed in tumor tissue from MPM patients. $\mathrm{CD}^{+}$human $T$ cells were retrovirally transduced with an anti-FAP-F19- $\triangle$ CD28/CD3Z-CAR. T cell function was evaluated in vitro by cytokine release and cytotoxicity assays. In vivo function was tested with an intraperitoneal xenograft tumor model in immunodeficient mice.

Results: FAP was found to be expressed in all subtypes of MPM. Additionally, FAP expression was evaluated in healthy adult tissue samples and was only detected in specific areas in the pancreas, the placenta and very weakly for cervix and uterus. Expression of the anti-FAP-F19- $\triangle C D 28 / C D 3 \zeta-C A R$ in $C D 8^{+} T$ cells resulted in antigen-specific IFNy release. Additionally, FAP-specific re-directed T cells lysed FAP positive mesothelioma cells and inflammatory fibroblasts in an antigen-specific manner in vitro. Furthermore, FAP-specific re-directed T cells inhibited the growth of FAP positive human tumor cells in the peritoneal cavity of mice and significantly prolonged survival of mice.

Conclusion: FAP re-directed $C D 8^{+} \mathrm{T}$ cells showed antigen-specific functionality in vitro and in vivo. Furthermore, FAP expression was verified in all MPM histotypes. Therefore, our data support performing a phase I clinical trial in which MPM patients are treated with adoptively transferred FAP-specific re-directed T cells.

\section{Introduction}

Malignant pleural mesothelioma (MPM) is a rare solid organ tumor, which originates from malignant transformed cells of the mesothelium [1]. A causal link to environmental factors has been established as at least 70\% of MPM patients have a definite record of chronic asbestos exposure [2]. MPM is considered an incurable disease with a median

\footnotetext{
* Correspondence: ulf.petrausch@usz.ch

${ }^{\dagger}$ Equal contributors

${ }^{5}$ Department of Immunology, University Hospital Zurich, Rämistr. 100, 8091

Zürich, Switzerland

Full list of author information is available at the end of the article
}

survival of 2 years even when intensive multi-modality treatment is performed [3-5]. Therefore, new therapeutic options are desperately needed.

Adoptive transfer of modified (re-directed) autologous $\mathrm{T}$ cells is a promising therapeutic strategy and objective responses were observed in preliminary clinical trials [6]. Re-directed $\mathrm{T}$ cells are (autologous) $\mathrm{T}$ cells that are retrovirally transduced to express a chimeric antigen receptor (CAR) specific for a target on the cell surface. CARs contain a single-chain Fv (scFv)-based molecule, which is specific for the target and coupled to T cell-specific signaling moieties such as $\mathrm{CD} 28$ and $\mathrm{CD} 3 \zeta$. The general

\section{Biomed Central}


functionality of these CARs is documented widely by recent literature [7]. The most striking success was observed in B cell lymphoma patients when CD19 was used as an immunological target [8]. However, also in solid cancer types such as ovarian cancer [9] and neuroblastoma [10] adoptive T cell transfer was tested. Recently, we successfully generated peptide-specific redirected T cells targeting NY-ESO-1 [11]. We tested different signaling domains of the chimeric antigen receptors (CARs) and could observe in vivo and in vitro immunological functionality [12].

To treat MPM with re-directed T cells, we set out to identify a surface protein that is universally expressed by the majority of MPM subtypes (epithelioid, sarcomatoid and biphasic). Fibroblast activation protein (FAP) was suggested to be a potential target antigen since FAP is widely expressed by various epithelial and mesenchymal cancer types [13]. FAP expression has been studied extensively by immunohistochemistry in the past [14] and is known to differ between cell types and even within the tumor tissue. Two patterns of expression are most frequently found: 1) FAP expression by cancer associated fibroblasts (CAFs) of the tumor stroma only (e.g. breast or colorectal cancer [15]) or 2) by both the tumor stroma and the tumor cells (e.g. sarcoma [16]). Altogether, FAP is expressed in about $90 \%$ of most common cancer types like breast, lung and colorectal cancer [17]. Its expression is also associated with chronic inflammation, tissue remodeling [18] and immune modulation in the tumor tissue [19]. We show here that FAP is expressed in all three major MPM histotypes, namely the epithelioid, sarcomatoid and the intermediate called biphasic.

FAP has been validated as target antigen in oncology by a monoclonal antibody called F19 (humanized version: sibrotuzumab) in different phase I/II clinical trials $[20,21]$. The antibody recognizes exclusively non-degraded human FAP. F19 accumulated specifically in the tumor tissue [22]; however, the clinical effect was marginal. The results indicated that the sole use of an antibody was not sufficient to induce a meaningful immunological antitumor response. Therefore, F19 was not further developed for clinical use [21].

We developed re-directed $\mathrm{T}$ cells with a CAR consisting of a scFv of the FAP-specific F19 antibody, a CD28 signaling domain lacking the lck binding moiety [23] and a CD3 $\zeta$ signaling domain. Our rational to develop FAP-specific re-directed T cells based on the F19 antibody was to utilize its already clinically proven specificity to target FAP positive tumor tissue combined with the immunological effector function of T cells. As observed by others our previous results clearly indicated increased antigen-specific function of re-directed $\mathrm{T}$ cells when the CAR contained a CD28 signaling domain [12,24]. Therefore, we decided to generate a second generation
CAR with a co-stimulating signal provided by the CD28 domain. For the first time we show here that re-directed $\mathrm{T}$ cells specific for FAP are cytotoxic towards FAP positive targets in vitro and control xenografted human FAP positive tumors in vivo.

\section{Material and methods \\ Cell lines}

293T and MSTO-211H were purchased from ATCC (Manassas, VA). HT1080FAP are HT1080 cells stably transfected with human FAP and HT1080PA are mocktransfected HT1080 cells [25]. T2-1B cells are HLA-A *02:01-positive T2 cells stably transfected with the HLAA*02:01-restricted NY-ESO-1 peptide 157-165 [26]. Tumor cell lines were cultivated in standard R10 media (RPMI1640 GlutaMax supplemented with $10 \%$ fetal bovine serum (FBS) (v/v), $50 \mathrm{U} / \mathrm{ml}$ penicillin and $50 \mu \mathrm{g} / \mathrm{ml}$ streptomycin; all obtained from Invitrogen (Karlsruhe, Germany)). For the culture of transfected HT1080 and T2 cells, $200 \mu \mathrm{g} / \mathrm{ml}$ G418 (Sigma-Aldrich Chemie GmbH, Buchs, Switzerland) or $2.5 \mu \mathrm{g} / \mathrm{ml}$ Hygromycin B (Invitrogen, Karlsruhe, Germany) was added, respectively.

To enable in vivo imaging, HT1080FAP and HT1080PA cells were stably transfected with a D-firefly luciferase encoding plasmid (pGL4.26 plasmid, Promega, Dübendorf, Switzerland which was kindly provided by Martin Pruschy, University Hospital Zurich, Switzerland) using Fugene transfection reagent (Roche Diagnostics $\mathrm{GmbH}$, Mannheim, Germany) according to the manufacturer's protocol. Forty-eight hours after transfection cells were submitted to selection using $150 \mu \mathrm{g} / \mathrm{ml}$ Hygromycin B. Cells were cloned by limited dilution and luciferase expression was monitored using Bright-Glo ${ }^{\mathrm{TM}}$ Luciferase Assay System and a GloMax Microplate Luminometer (both Promega, Madison, WI) according to the manufacturer's protocol. Clones with luciferase activity underwent two more rounds of limited dilution followed by further testing for luciferase activity. Finally, a stable HT1080FAPluc and HT1080PA-luc clone were selected that exhibited high luciferase activity and maintained this over months even when cultured in the absence of Hygromycin B. The resultant HT1080FAP-luc and HT1080PA-luc cells were cultivated in standard R10 media supplemented with $200 \mu \mathrm{g} / \mathrm{ml} \mathrm{G418}$ and $150 \mu \mathrm{g} / \mathrm{ml}$ Hygromycin B.

Rheumatoid arthritis synovial fibroblasts originating from tissues obtained during joint replacement surgery (Schulthess Clinic, Zurich, Switzerland) were isolated for cell cultures as described previously [27]. Briefly, synovial tissues were digested with dispase at $37^{\circ} \mathrm{C}$ for 60 minutes. After washing, cells were grown in Dulbecco's MEM NUT MIX-F12 (Invitrogen, Karlsruhe, Germany) supplemented with $10 \% \mathrm{FBS}, 50 \mathrm{U} / \mathrm{ml}$ penicillin, $50 \mu \mathrm{g} / \mathrm{ml}$ streptomycin and $10 \mathrm{mM}$ HEPES (Invitrogen, Karlsruhe, Germany). 


\section{Antibodies and reagents}

Antibodies for flow cytometry were purchased from eBioscience (San Diego, CA) (anti-human CD8a-FITC), Invitrogen (Karlsruhe, Germany) (LIVEDEAD Fixable Aqua Dead Cell Stain Kit) and Southern Biotech (Birmingham, AL) (anti-human IgG-PE). Analysis of FAP expression was performed using the humanized anti-F19 antibody [20] (kindly provided by Andrew Scott, Ludwig Institute for Cancer Research, Australia), whereas MabThera (Rituximab; anti CD20 mAb; Roche Pharma AG, Reinach, Switzerland) was used as a negative control antibody. Both antibodies were directly labeled with Alexa Fluor 647 (Alexa Fluor 647 Antibody Labeling Kit; Invitrogen, Karlsruhe, Germany) according to the manufacturer's protocol. Murine F19 antibody [25] (kindly provided by Andrew Scott, Ludwig Institute for Cancer Research, Australia) was used as primary antibody for immunohistochemistry staining, and the murine HD6 monoclonal antibody served as a control antibody [28]. A biotin-labeled goat anti mouse IgG (Fcy fragment specific) was used as secondary antibody (Jackson ImmunoResearch, Suffolk, UK). Recombinant human FAP was kindly provided by Andrew Scott, Ludwig Institute for Cancer Research, Australia.

\section{Generation of the FAP-specific chimeric antigen receptor (CAR)}

The variant heavy and the variant light chain of humanized F19 [21] have been converted into a scFv fragment and were flanked with NcoI and BamHI restriction sites. This construct was cloned into the pBullet vector [29] containing a human $\Delta \mathrm{CH} 2 / \mathrm{CH} 3$ domain, a $\Delta \mathrm{CD} 28$ [23] and a CD3 $\zeta$ signaling domain (kindly provided by Hinrich Abken, University of Cologne, Germany). The human $\mathrm{CH} 2 / \mathrm{CH} 3$ domain has been modified to reduce $\mathrm{Fc} \gamma \mathrm{R}$ binding and thereby minimizing the risk of off-target $\mathrm{T}$ cell activation by CAR binding to $\mathrm{Fc} \gamma \mathrm{R}^{+}$cells [30]. Furthermore, the CD28 binding domain for lck was corrupted by site directed mutagenesis to avoid IL-2 release and subsequent persistence of $\mathrm{T}_{\text {reg }}$ cells [23].

The resulting chimeric antigen receptor construct was

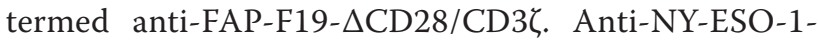
T1- $\triangle \mathrm{CD} 28 / \mathrm{CD} 3 \zeta$ recognizing the HLA-A*02:01/ NYESO- $1_{157-165}$ peptide complex served as a control construct [12]. It displays the same genetic modifications in the downstream $\mathrm{CH} 2 / \mathrm{CH} 3$ and $\mathrm{CD} 28$ lck domains.

\section{Retroviral transduction of peripheral blood $\mathrm{CD}^{+} \mathrm{T}$ cells}

Retroviral transduction of human peripheral $\mathrm{CD}^{+} \mathrm{T}$ cells was performed as previously described [12] with following minor modifications. $\mathrm{CD}^{+} \mathrm{T}$ cells were purified from healthy donor buffy coats using anti-CD8 labeled magnetic beads and MACS technology (Miltenyi, Bergisch Gladbach, Germany). Positive selection with anti-human
CD8 microbeads typically resulted in a $\geq 95 \%$ pure $\mathrm{CD}^{+}$ population. $\mathrm{CD}^{+} \mathrm{T}$ cells were subsequently activated with CD3/CD28 human $\mathrm{T}$ cell expander beads (Invitrogen, Germany) at a bead to cell ratio of 1:5 and $100 \mathrm{IU} / \mathrm{ml} \mathrm{IL}-2$ (ImmunoTools, Friesoythe, Germany) in standard R10 media for $48 \mathrm{~h}$. Activated $\mathrm{CD}^{+} \mathrm{T}$ cells were retrovirally transduced for 48 hours in the presence of $100 \mathrm{IU} / \mathrm{ml}$ IL-2 by co-cultivation with $293 \mathrm{~T}$ cells that were transiently producing high titers of infectious retrovirus carrying the genomic information of the chimeric antigen receptors. $\mathrm{CD}^{+} \mathrm{T}$ cells were expanded for 2 more days in R10 plus $100 \mathrm{IU} / \mathrm{ml} \mathrm{IL}-2$ before harvest and subsequent application in experiments.

\section{Flow cytometry}

Flow cytometry was carried out as described previously [12]. Live/dead staining was performed using the LIVE/ DEAD fixable Aqua Dead Cell Stain Kit according to the manufacturer's protocol. BrdU Proliferation assay were performed with the FITC BrdU flow kit (BD Pharmingen, San Diego, CA) according to the manufacturer's instruction. Flow cytometric measurements were performed using a FACSCanto II or FACSCalibur machine (BD Biosciences, San Diego, CA). Data were analyzed using FlowJo software (Tree Star, Ashland, OR).

\section{Cytokine assays}

Cytokine production was assessed by sandwich ELISA assays. Supernatants of co-cultivated effector and target cells were collected after 24 hours of incubation. IFN $\gamma$ and IL-2 levels were detected using BD OptEIA set human IFN $\gamma$ and BD OptEIA set human IL-2 kits, respectively, according to the manufacturer's instruction (BD Biosciences, San Diego, CA).

\section{Immunohistochemistry}

To study potential off-target sites of FAP re-directed $\mathrm{T}$ cells, we purchased frozen tissue arrays that contained human adult normal tissue (BioChain, Newark, CA) and stained them for FAP expression. To study expression of FAP in MPM, a total of 9 fresh-frozen samples from malignant pleural mesothelioma patients were retrieved from the biobank of the Institute of Surgical Pathology, University Hospital Zurich.

To perform immunohistochemistry acetone-fixed tissue slides were developed employing the Vectastain ABC Kit Peroxidase Mouse IgG (VECTOR LABORATORIES, Burlingame, CA) according to the manufacturer's protocol with minor modifications. Briefly, slides were additionally incubated with an avidin and a biotin block (both VECTOR LABORATORIES, Burlingame, CA) for $10 \mathrm{~min}$ at RT. Two $\mu \mathrm{g} / \mathrm{ml}$ murine F19 or murine HD6 antibody as negative control in $20 \%$ of blocking buffer (10\% rabbit serum (VECTOR LABORATORIES, Burlingame, CA), 5\% 
milk powder (Roth, Karlsruhe, Germany) in PBS) were added as primary antibody overnight at $4^{\circ} \mathrm{C}$. The secondary biotin-goat anti mouse Fc antibody was diluted 1:2000 in 20\% of blocking buffer. ImmPACT DAB, SK4105 (VECTOR LABORATORIES, Burlingame, CA) was used as peroxidase substrate kit according to the manufacturer's protocol.

The slides were analyzed with a high-speed wide field fluorescence microscope Leica LX and pictures were recorded using a Leica DFC 350 FX camera system (both Leica Microsystems, Heerbrugg, Switzerland).

\section{Europium release assay}

Specific cytotoxicity of re-directed $\mathrm{T}$ cells was analyzed by a europium release assay (Perkin Elmer, Waltham, MA) as previously described [12]. HT1080FAP-luc, HT1080PAluc, MSTO- $211 \mathrm{H}, \mathrm{T} 2-1 \mathrm{~B}$ and primary rheumatoid fibroblasts served as target cells for anti-FAP-F19- $\triangle$ CD28/CD3 $\zeta$ and anti-NY-ESO-1-T1- $\triangle \mathrm{CD} 28 / \mathrm{CD} 3 \zeta$ re-directed T cells. All cell lines were labeled with 2,2':6,2"-terpyridine-6,6"dicarboxylic acid acetoxymethylester (BATDA) for $30 \mathrm{~min}$ at $37^{\circ} \mathrm{C}$. Target cells were seeded at a density of $10^{4}$ cells per 96-round bottom-well and co-cultured with effector cells at different effector:target ratios for $4 \mathrm{~h}$ at $37^{\circ} \mathrm{C}$ in $\mathrm{R} 10$ media followed by supernatant analyses in a time-resolved Victor $^{2}$ flourometer (Perkin Elmer, Waltham, MA). The specific cytolysis of target cells (\%) was calculated by the equation: 100x[experimental release (counts) - spontaneous release(counts)]/[maximum release (counts) - spontaneous release(counts)]

\section{Therapy of xenografted $\mathrm{FAP}^{+}$human tumors}

NOD.Cg-Prkdc ${ }^{\text {sid }} \mathrm{Il}_{2 \mathrm{rg}}{ }^{\mathrm{tm} 1 \mathrm{~W}^{\mathrm{j}} \mathrm{l}} / \mathrm{SzJ}$ mice, commonly known as NOD.scid.ycKO (NSG), were originally obtained from Jackson Laboratories (Bar Harbor, ME, USA), bred and maintained at the University Hospital Zurich under specific pathogen-free conditions. HT1080FAP-luc tumor cells $\left(10^{6}\right.$ cells per mouse) were co-injected intraperitoneally with re-directed T cells at an effector to target ratio of 5:1. Tumor burden was monitored by body weight measurements and in vivo bioluminescence imaging. For that purpose, mice were anesthetized with $2 \%$ isoflurane and i.p. injected with $150 \mathrm{mg} / \mathrm{kg}$ D-Luciferin (Caliper Life Sciences, Hopkinton, MA) and signals were visualized using IVIS 200 Caliper (Caliper Life Sciences, Hopkinton, MA). Monitoring of mice was started immediately after D-Luciferin injection and lasted up to $20 \mathrm{~min}$ to obtain the peak photon emission of each animal. Bioluminescence signals were collected and converted to photons/ second $/ \mathrm{cm}^{2} /$ steradian in order to normalize each setting for F-stop, exposure time, binning and animal size using Living Image 3.2 (Caliper Life Sciences, Hopkinton, MA). A constant region of interest was designated around the torso of each animal in order to avoid any incoherence.
For imaging purposes, a pseudocolor map representing light intensity was superimposed over a whole-body image. Age-matched mice were used for all experiments. Tumorbearing mice were euthanized if their body weight increased or decreased more than $15 \%$ if compared to the weight of non-diseased, age-matched mice or if mice were confined in their normal behavior by tumor growth. Animal experiments were performed according to Swiss federal and cantonal laws on animal protection.

\section{Statistical analysis}

Data were analyzed with Graph Pad Prism version 5.00 for Windows (GraphPad Software, San Diego, CA). Student's unpaired 2-tailed t-tests were performed between two groups of interest. Survival analysis was performed employing Kaplan Meier survival curves and significance between two variables was calculated using the log-rank test.

\section{Results}

Malignant pleural mesothelioma expressed fibroblast activation protein in the tumor-associated stroma and on tumor cells

We analyzed the three distinct histologic subtypes of malignant pleural mesothelioma from a total of $18 \mathrm{pa}-$ tient biopsies for FAP expression. The MPM histosubtype was determined by a panel of positive and negative immunohistochemistry (IHC) markers (Calretinin, CK5/6 und TTF1) and morphology. Different cell types in the biopsies were identified by morphology. Staining for FAP was scored by the reference pathologist of our institution (A.S.) in a three-tiered system (+: faint, ++ moderate, and +++ strong).

Eight out of eight epithelioid MPM specimens showed faint to strong FAP expression on tumor cells and a moderate to strong expression on stromal cells (Figures 1a,b). Two out for four sarcomatoid MPM samples displayed moderate membranous expression of FAP on tumor cells as well as on stromal cells (Figures 1c,d). All six biphasic MPM samples showed moderate to strong FAP expression on the tumor cells and a strong expression in the stromal compartment (Figures 1e,f). In total, we discovered FAP expression on tumor cells and stroma in 16 out of $18 \mathrm{pa}-$ tient MPM samples.

To evaluate FAP expression in healthy adult tissue we screened 20 organ specimens for FAP expression to determine possible targets of toxic side-effects (adrenal, ovary, pancreas, thyroid, uterus, cervix, breast, placenta, cerebrum, cerebellum, lung, spleen, heart, skin, skeletal muscle, kidney, stomach, small intestine, liver and salivary gland). Specific FAP expression was only present in specific areas of the pancreas and placenta and very weakly for cervix, and uterus (Additional file 1: Figure S1). 


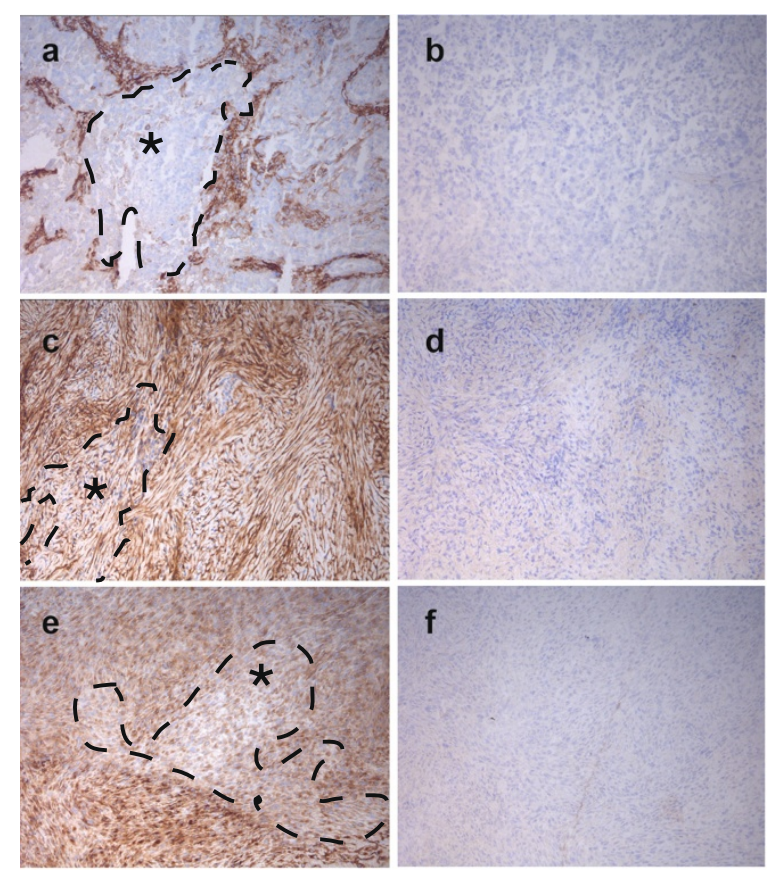

Figure $1 \mathrm{IHC}$ of fresh-frozen malignant pleural mesothelioma patient sections. A, $\mathbf{c}$ and $\mathbf{e}$ were stained with the FAP recognizing murine F19 antibody, whereas $\mathbf{b}, \mathbf{d}$, $\mathbf{f}$ represent the secondary system only. All three histosubtypes of MPM have been analyzed: epithelioid (a, b), sarcomatoid (c, d) and bi-phasic (e, f). Regions marked with * indicate areas of predominant tumor cell location.

\section{Generation of FAP-specific, re-directed $\mathrm{CD}^{+} \mathrm{T}$ cells}

We generated re-directed $\mathrm{T}$ cells expressing a CAR consisting of a single-chain $\mathrm{Fv}$ (scFv) molecule recognizing FAP. The scFv is linked to a modified human $\mathrm{CH} 2 / 3$ immunoglobulin domain to reduce FcR $\gamma$ binding and a $\triangle \mathrm{CD} 28$ co-stimulatory domain which lacks the lck binding moiety. The last moiety of the construct is the CD3 $\zeta$ domain which facilitates intracellular signaling (antiFAP-F19- $\triangle$ CD28/CD3ל). As a control construct we cloned the $\mathrm{scFv}$ of the recently published anti-NY-ESO-1-T1$\mathrm{CD} 28 / \mathrm{CD} 3 \zeta$ in the $\Delta$ backbone which in the following is termed anti-NY-ESO-1-T1- $\triangle \mathrm{CD} 28 / \mathrm{CD} 3 \zeta$ [12]. A schematic representation of the CAR re-directed $\mathrm{T}$ cells is given in Additional file 1: Figure S2.

We isolated $\mathrm{CD}^{+} \mathrm{T}$ cells from human peripheral blood and retrovirally transduced them to achieve cell surface expression of CARs which was assessed by detection of the modified human $\mathrm{CH} 2 / 3$ immunoglobulin domain (hIgG) using flow cytometry. After transduction, $46.7 \%$ of anti-FAP-F19- $\triangle$ CD28/CD3 $\zeta$ re-directed $C D 8^{+} \mathrm{T}$ cells stained for hIgG (Figure $2 \mathrm{~b}$ ) and $52.6 \%$ of $\mathrm{CD}^{+} \mathrm{T}$ cells carried the anti-NY-ESO-1-T1- $\triangle \mathrm{CD} 28 / \mathrm{CD} 3 \zeta$ CAR (Figure 2c). Non-transduced $\mathrm{CD}^{+} \mathrm{T}$ cells did not stain for hIgG (Figure 2a). The range of transduction efficiency for anti-FAP-F19- $\triangle$ CD28/CD3 $\zeta$ was $31.31 \pm 10.69$ (SD) and for anti-NY-ESO-1-T1- $\triangle$ CD28/CD3 $32.55 \pm 10.31$ (SD) (Figure 2b,c). To investigate the functionality of the generated re-directed $\mathrm{T}$ cells we co-cultivated effector cells and target cells at a 1:1 ratio. Both constructs showed antigen-specific IFN $\gamma$ release (Figure 2d). Furthermore, to determine the effect of abrogating the lck-binding domain, we activated $\mathrm{CD}^{+} \mathrm{T}$ cells expressing anti-

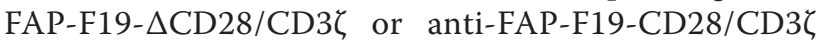
(intact lck-signaling) with recombinant human FAP. Measurement of IL-2 release demonstrated a significant reduction in IL-2 production in anti-FAP-F19- $\triangle$ CD28/ CD3 $\zeta$ re-directed T cells. However, anti-FAP-F19- $\triangle$ CD28/ $\mathrm{CD} 3 \zeta$ re-directed $\mathrm{T}$ cells secreted measurable basal amounts of IL-2 (Figure 2f). Since we observed reduced IL-2 production we investigated the ability of antiFAP-F19- $\triangle$ CD28/CD3 $\zeta$ re-directed $T$ cells to proliferate in the absence of exogenous IL-2. Up to day 6 during antigen-specific stimulation the addition of exogenous IL-2 did not increased the proliferation capacity of antiFAP-F19- $\triangle$ CD28/CD3 $\zeta$ re-directed $T$ cells (Figure 2f). To investigate the longevity of re-directed $\mathrm{T}$ cells without cytokine support we analyzed the in vitro survival of anti-FAP-F19- $\triangle$ CD28/CD3ל re-directed T cells with or without supplementation of $100 \mathrm{IU} / \mathrm{ml} \mathrm{IL-2} \mathrm{employing}$ live/dead staining of $\mathrm{CD}^{+} \mathrm{T}$ cells. The addition of IL-2 led in all cases to sustained survival of 70-98\% $\mathrm{CAR}^{+}$as well as $\mathrm{CAR}^{-} \mathrm{T}$ cells (Figure $2 \mathrm{~d}$ ) whereas no IL-2 supplementation resulted in early loss of $\mathrm{CAR}^{+} \mathrm{T}$ cells starting around day 3 (Figure 2e). CAR ${ }^{-} \mathrm{T}$ cells showed a high percentage of living cells out to day 8 . However, between day 8 and 12 all IL- 2 deprived CD8 $\mathrm{T}$ cells were lost regardless of their transduction state (Figure 2e).

\section{FAP-specific, re-directed T cells lysed FAP positive target cells}

We performed europium cytotoxicity assays to determine antigen-specific cytotoxicity of the re-directed $\mathrm{T}$ cells in vitro. Therefore, we used different target cells that exhibited various levels of FAP expression. As expected from FAP positive IHC of MPM specimens the mesothelioma derived cell line MSTO-211H showed FAP expression (Additional file 1: Figure S3c). The FAP transduced cell line HT1080FAP-luc (Additional file 1: Figures S3a,b) served as positive control. As expected from previous reports [29] primary fibroblasts from patients with active joint inflammation also stained positive for FAP (Additional file 1: Figure S3e). We employed as control cell lines HT1080PA-luc and T2-1B known to be negative for FAP expression (Additional file 1: Figures S3b,f and g). Importantly, co-cultivation of the mesothelioma cell line MSTO-211H with anti-FAP-F19$\triangle \mathrm{CD} 28 / \mathrm{CD} 3 \zeta$ re-directed $\mathrm{T}$ cells resulted in specific lysis 


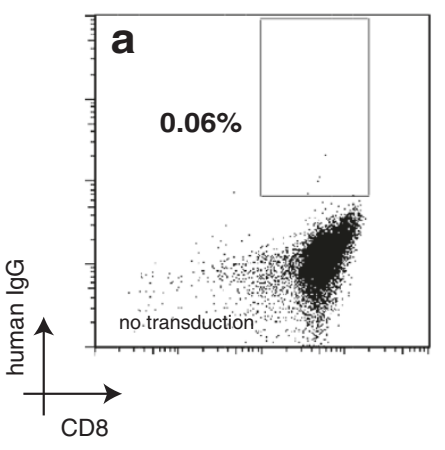

d

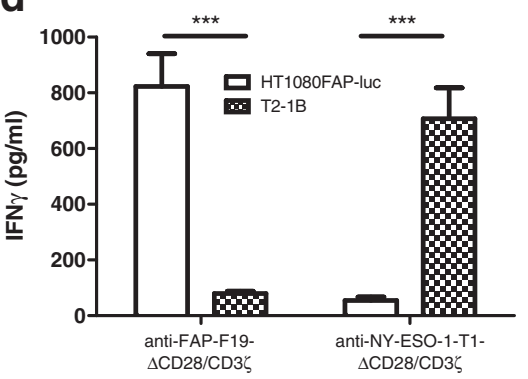

f

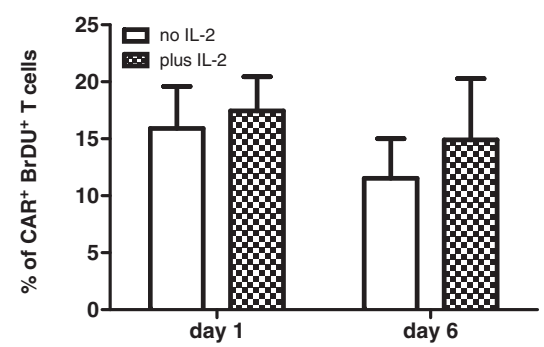

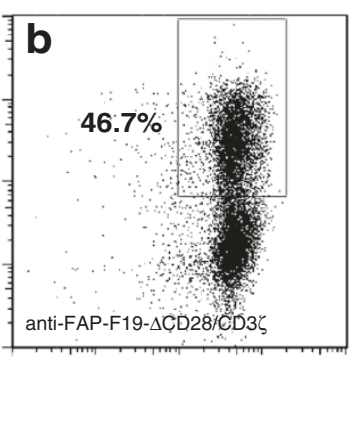

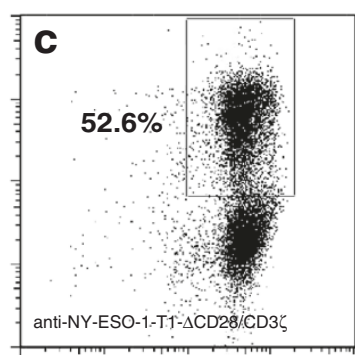

e

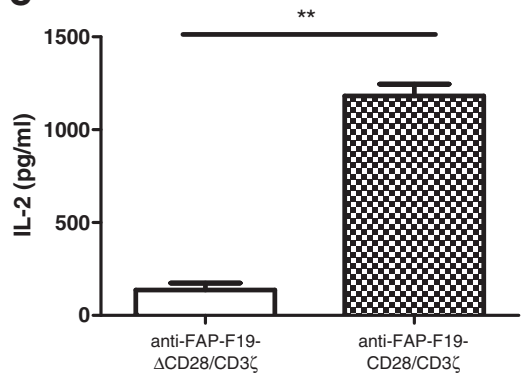

Figure 2 Transduction efficacy and purity of CD8 $T$ cells $(\mathrm{a}-\mathrm{c})$ and functional activity of CAR transduced $\mathrm{T}$ cells in vitro (d, e, $\mathrm{f}$ ). Transduction efficacy was assessed by staining the $\mathrm{CH} / 3$ immunoglobulin linker domain with anti-hlgG mAb and with anti-CD8 $m A b(n=10)$. A shows non-transduced T cells, whereas $\mathbf{b}$ displays T cells transduced with the FAP-specific anti-FAP-F19- $\triangle C D 28 / C D 3 \zeta$ CAR and $\mathbf{c}$ with the NY-ESO-1 specific anti-NY-ESO-1-T1- $\triangle$ CD28/CD3Z CAR. $24 \mathrm{~h}$ co-cultivation of re-directed T cells with the target cell lines HT1080FAP-luc and T2-1B was analyzed for IFNY release $(n=5)(\mathbf{d})$. Comparison of IL-2 production of anti-FAP-F19- $\triangle$ CD28/CD3Z and anti-FAP-F19-CD28/CD3Z after $24 \mathrm{~h}$ of co-cultivation with HT1080FAP-luc $(n=2)(e)$. Proliferation of anti-FAP-F19- $\triangle C D 28 / C D 3 \zeta$ re-directed T cells after stimulation with recombinant human FAP $(1 \mathrm{\mu g} / \mathrm{ml})$ in the absence and presence of $\mathrm{IL}-2(100 \mathrm{IU} / \mathrm{ml})$ at indicated time points $(n=2)(\mathbf{f})$. Error bars were calculated as mean + SD $\left({ }^{* *} p<0.001,{ }^{* *} p<0.01\right.$ as calculated by Student's unpaired 2 tailed t-tests).

of MSTO-211H cells in a dose dependent manner (Figure 3a). In addition, HT1080FAP and primary fibroblasts were also specifically lysed (Figures 3b,c).

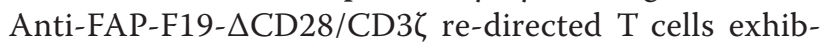
ited only background lysis when co-cultivated with the FAP negative cell lines HT1080PA-luc and T2-1B

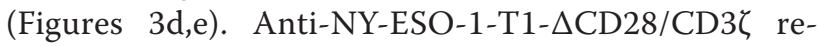
directed $\mathrm{T}$ cells did not recognize any target cell lines besides T2-1B cells which express the HLA-A*02:01/ NY-ESO-1 157-165 peptide complex as their specific target structure. These data show that FAP-specific redirected $\mathrm{T}$ cells specifically and efficiently lyse FAP positive targets in vitro.
Adoptive therapy with anti-FAP-F19- $\triangle$ CD28/CD3Z re-directed $T$ cells resulted in significant delay of $\mathrm{FAP}^{+}$tumor outgrowth in the peritoneum of NSG mice

Our findings above demonstrated a FAP-specific redirection of $\mathrm{T}$ cells in vitro and a moderate to high FAP expression in MPM samples. The proposed clinical trial is designed to inject re-directed $\mathrm{T}$ cells in the pleural space [31]. However, as the pleural space is difficult to assess in mice we established a model in the peritoneum to mimic adoptive transfer of $\mathrm{T}$ cells in a body cavity. Therefore, we evaluated the anti-tumor activity of FAP specific re-directed $\mathrm{T}$ cells by establishing an i.p. tumor model which constitutively expressed FAP as well as 

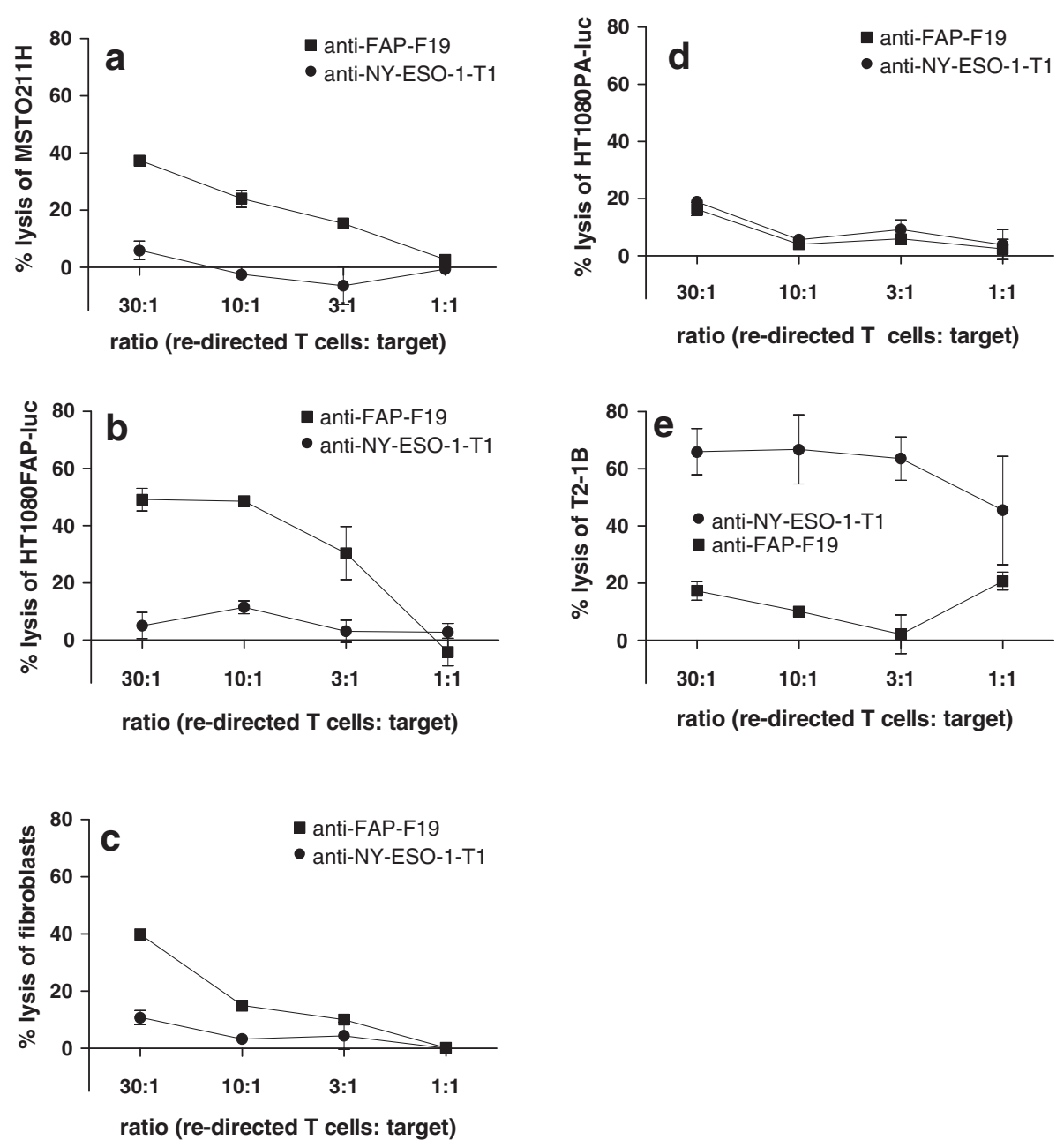

Figure 3 Antigen-specific cytolysis of anti-FAP-F19- $\triangle$ CD28/CD3 , re-directed T cells. Re-directed T cells recognizing FAP (anti-FAP-F19- $\triangle C D 28 / C D 3 \zeta$ (square) and NY-ESO-1 ${ }_{157-165}$ peptide in the HLA-A*02:01 context (anti-NY-ESO-1-T1- $\triangle$ CD28/CD3C) (circle) were cultured with MSTO-211H cells (a, FAP positive), HT1080FAP-luc cells (b, FAP positive), primary fibroblasts (c, FAP positive), HT1080PA-luc cells (d, FAP negative) and T2-1B cells (e, FAP negative but HLA-A*02:01, NY-ESO-1 $1_{157-165}$ peptide positive) at different effector to target ratios and analyzed after $4 \mathrm{~h}$ of incubation in a europium release assay $(n=2)$. Error bars were calculated as mean + SD.

luciferase for in vivo detection of tumor cells. Injection of HT1080FAP-luc cells into the peritoneum resulted in progressively growing tumors and mice had to be euthanized within three weeks in accordance to predefined end-points (data not shown). HT1080FAP-luc cells and FAP-re-directed T cells or NY-ESO-1-re-directed T cells were co-injected i.p. and monitored by serial bioluminescent imaging as indicated (Figure 4a). A significant delay and/or protection of tumor outgrowth was detected in the group treated with anti-FAP re-directed $\mathrm{T}$ cells, whereas the tumor grew progressively in the control group injected with NY-ESO-1- re-directed T cells. In this allogeneic setting of $\mathrm{T}$ cells and tumor cells, NY-ESO-1specific re-directed $\mathrm{T}$ cells displayed no specific anti-tumor effect but prolonged the survival compared to the saline control group (data not shown). Most importantly, there was a significant difference between the anti-FAP and the anti-NY-ESO-1 treated group from day 28 on $(\mathrm{P}=0.041$, data not shown). In addition, the survival of the experimental groups was monitored. Based on pre-defined endpoints in accordance with animal protection mice were euthanized (Figure 4b). The survival after injection of antiFAP re-directed $\mathrm{T}$ cells was significantly longer compared to the control group treated with anti-NY-ESO-1 redirected $\mathrm{T}$ cells $(\mathrm{p}=0.007)$. Median $50 \%$ survival was not reached in the group treated with anti-FAP re-directed T cells.

\section{Discussion}

MPM is still a disease in which even the combination of all three conventional branches of oncologic treatment, surgery, chemotherapy and radiotherapy have to 


\section{a}

day 4

anti-FAP-F19- $\Delta$ CD28/CD3 $\zeta$

day 9
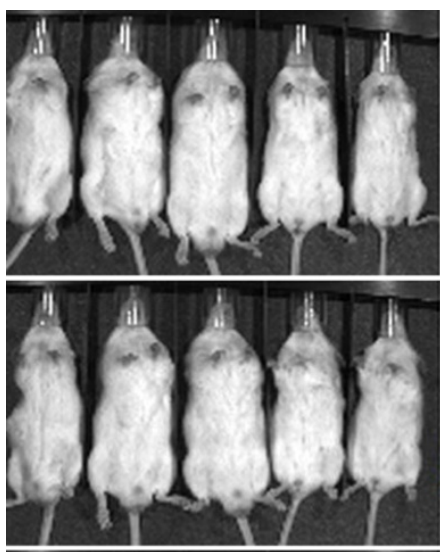

day 14

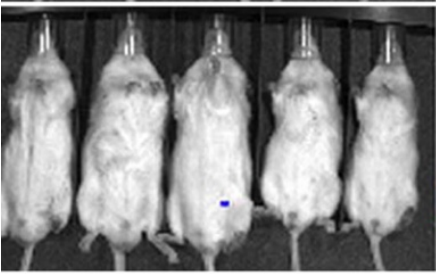

day 21

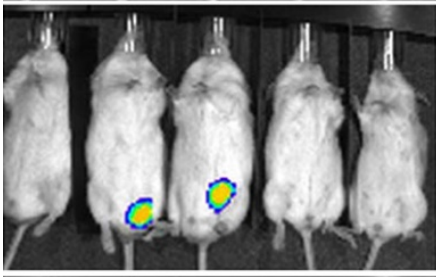

day 28
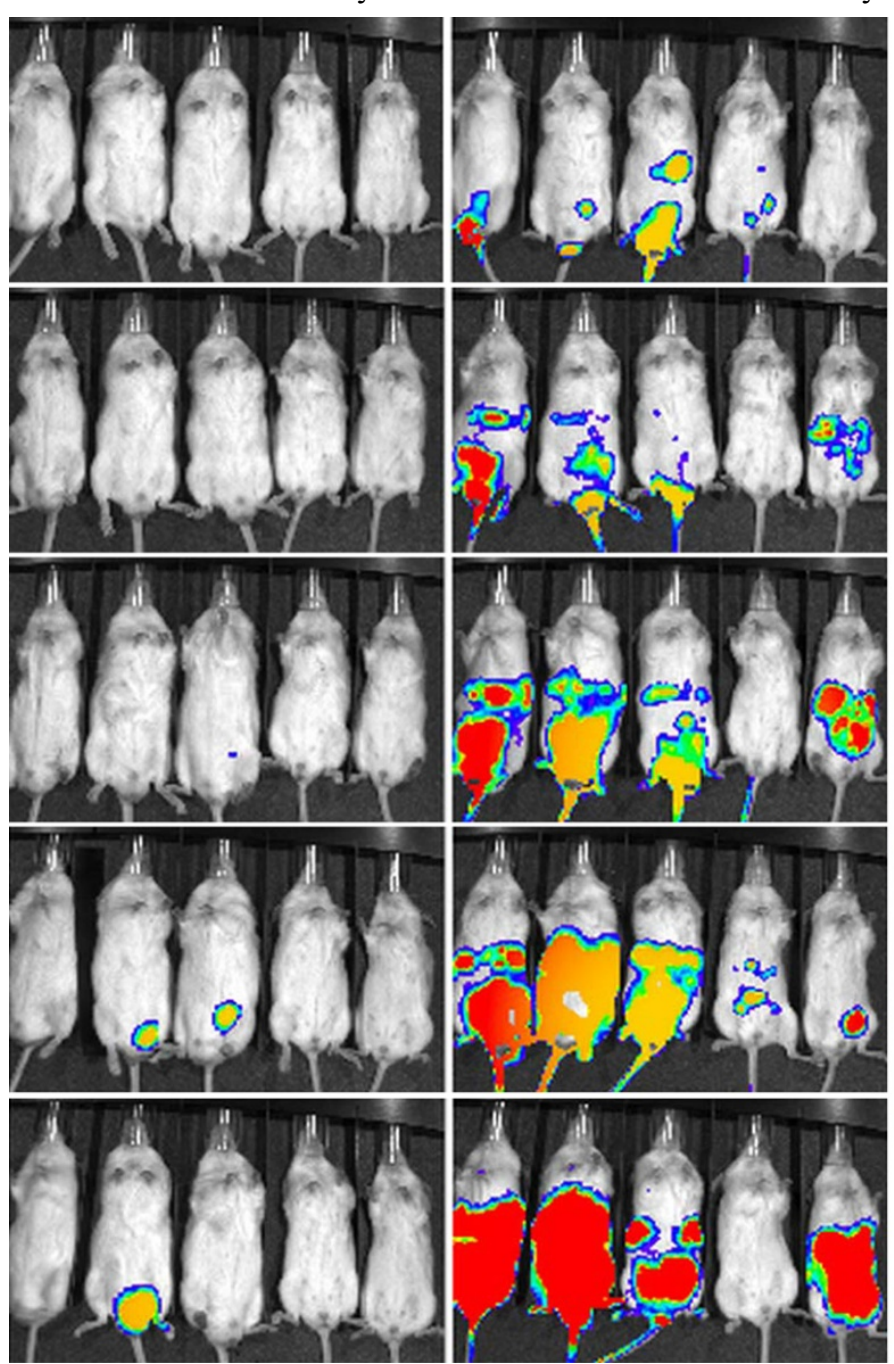

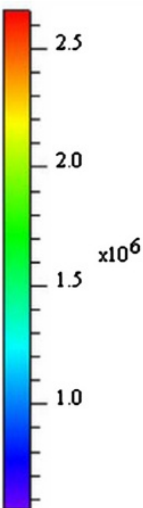

$\mathrm{p} / \mathrm{sec} / \mathrm{cm}^{\wedge} 2 / \mathrm{sr}$

\section{Color Scale \\ Min $=5.52 e 5$} $\operatorname{Max}=2.66 \mathrm{e} 6$

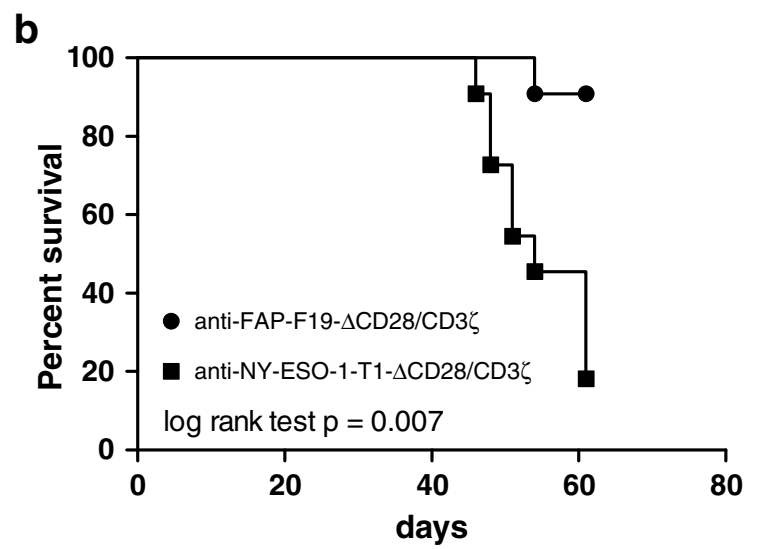

Figure 4 Xenograft model of disseminated i.p. tumors. Anti-FAP-F19- $\triangle$ CD28/CD3Z or anti-NY-ESO-1-T1- $\triangle C D 28 / C D 3 \zeta$ re-directed T cells were co-injected i.p. with $1 * 10^{6}$ HT1080FAP-luc tumor cells at an effector to target ratio of 5:1. HT1080FAP-luc tumor cells were recorded by bioluminescence imaging in the same mouse at the indicated days starting day 4 after cell injection (a). A total of 11 mice per experimental setting were treated with re-directed T cells from 2 different donors (donor 1: 6 mice per group, donor 2: 5 mice per group). The median survival of mice was determined by Kaplan-Meier analysis (b). Significance between cohorts was determined by log rank test. 
be considered a palliative attempt and other therapeutic options have to be evaluated [32]. Beside therapies targeting molecular pathways of the malignant cells [33], immunotherapy is a novel therapeutic strategy to fight MPM [34]. Most of the so far tested approaches focus on the induction of an active-specific immune response. As an alternative approach, passive adoptive immune therapy could be proposed. Therefore, we investigated the potential therapeutic effect of FAP-specific redirected T cells as a new option for treatment of MPM. All three histological subtypes of MPM demonstrated FAP expression by the tumor stroma and by most tumor cells. Garin-Chesa and colleagues had demonstrated FAP expression in 7 MPM samples in the tumor stroma as well as on tumor cells with variable FAP expression levels [13]. T cells expressing anti-FAP CARs at high level were generated by standard procedures and these re-directed $\mathrm{T}$ cells were antigen-specific as characterized by their specific in vitro killing of FAP positive mesothelioma cells. To examine the therapeutic efficacy of FAP-specific re-directed $\mathrm{T}$ cells in vivo, we adoptively transferred re-directed $\mathrm{T}$ cells into the peritoneal cavity of mice bearing FAP + tumors. In this setting, FAP-specific re-directed $\mathrm{T}$ cells showed strong therapeutic potential, preventing the growth of FAP + tumors and increasing survival of mice.

MPM derives from the mesothelial cell lineage of the serous membranes of the pleura. This process causes a chronic stimulation of the serous membranes resulting in pleural effusion in the majority of clinical cases. Since our first planned clinical protocol (manuscript is published: Petrausch U, Schuberth PC, Hagedorn C, Soltermann A, Tomaszek S, Stahel R, Weder W, Renner C: Re-directed T cells for the treatment of fibroblast activation protein (FAP)-positive malignant pleural mesothelioma (FAPME-1). BMC Cancer 2012, 12:615.) is designed to test the safety of FAP-specific re-directed T cells after injection in the pleural effusion, we developed an intra-peritoneal model for the adoptive transfer of $\mathrm{T}$ cells to model the function of these cells in a body cavity. As shown by June and coworkers for mesothelin-specific re-directed $\mathrm{T}$ cells [35], the application of FAP-specific re-directed T cells resulted in the specific lysis of the respective target cells. Since the chosen model system tested human CD8 positive cells in a murine xenograft model with human tumor cells, the potential for allogeneic effects is a major concern. To control for this allogeneic effect, we used our previously, extensively characterized HLA-A*02:01/NY-ESO- $1_{157-165}$ peptide-specific re-directed $\mathrm{T}$ cells because these cells displayed some allogeneic reactivity [12]. Importantly, HLA-A*02:01/NY-ESO-1 ${ }_{157-165}$ peptide-specific re-directed $\mathrm{T}$ cells could not control the growth of FAP + tumor cells demonstrating the antigen-specific therapeutic effect of our re-directed FAP-specific T cells.
Adoptive transfer of $\mathrm{T}$ cells with a new specificity generated by gene transfer is associated with two major concerns. First, the new specificity can cause on-target off-site effects resulting in T-cell mediated organ damage as documented by recent publications [36]. Therefore, the exploration of off-site target expression is of crucial interest. In healthy tissue, low-level expression of FAP could only be detected in pancreas, placenta, cervix and uterus. We have not tested tissue from chronically inflamed tissue. Chronic inflammation of tissues causes activation of fibroblasts as part of the remodeling process which occurs during inflammation [18]. To estimate the effect of re-directed FAP-specific T cells in chronically inflamed tissue, we used activated fibroblasts from patients with rheumatoid arthritis out of the effusion from inflamed joints. As reported, the herein used activated fibroblasts isolated from different donors expressed FAP [37]. Therefore, the strong and antigen-specific lysis of fibroblasts derived from inflamed tissue by re-directed FAP-specific $\mathrm{T}$ cells was expected. This observation indicates the potential for adverse off-site effects in tissues with activated fibroblasts. The F19 CAR cannot be used in murine models of inflammation since the $\mathrm{scFv}$ only recognizes the human version of FAP. Since no other model for toxicity estimation is available with the F19 CAR we performed cytotoxicity assay with human fibroblast and implemented strict exclusion criteria for our planed clinical study. All patients with chronic inflammatory diseases have been excluded. Patients with coronary heart disease (CHD), stroke or peripheral vascular disease (PVD) also have to be excluded since expression of FAP was detected in atherosclerotic vessels $[31,38,39]$.

To further minimize potential long-term off-target toxicity we evaluated the therapeutic potential of a second generation CAR with a CD28 co-stimulatory domain. We and other have seen, that re-directed CD8+ T cells with CAR containing a CD28 moiety eliminated target cells more effectively than re-directed T cells with a CD3 domain alone $[12,40]$. CD28 signaling also induces IL-2 production, which leads to expansion of cells [41]. The herein used CAR lacks the lck domain, avoiding IL-2 induction [23]. The co-stimulation by 4-1BB also enhances persistence and clonal expansion of re-directed $\mathrm{T}$ cells, whereas cytotoxic activity is less impacted [42]. Based on the most recent literature we designed a FAP-specific CAR causing cell lysis by CD8+ $\mathrm{T}$ cells and minimal long-term persistence. Based on the existing experience this allows a clinical phase I trial to first test a CAR recognizing FAP, for which no clinical data are available so far [6].

The second concern is the gene transfer itself. The clinical course of patients with X-linked immunodeficiency after gene transfer in hematopoietic stem cells resulted in the development of leukemia in 4 out of 9 cases [43]. Most recently, the safety of retroviral gene transfer in $\mathrm{T}$ cells in 
clinical settings was confirmed by measuring 540 patient years of follow up [44]. During this time, retroviral gene transfer resulted in no malignant transformation even in cases with very high numbers of integrations per cell ( $2 \times 10^{11}$ integration site per cell). These recent data suggest that $\mathrm{T}$ cells can be safely transduced by retroviral transfer. Additionally, our re-directed FAP-specific T cells showed limited in vitro survival in the absence of exogenous IL-2 suggesting that retroviral transduction did not result in altered survival control. The limited life span implies a predominant effector phenotype of terminally differentiated $\mathrm{T}$ cells as was previously shown for HLA-A*02:01/ NY-ESO- $1_{157-165}$ re-directed T cells [12]. These data also suggest that gene transfer did not alter this differentiation program of $\mathrm{T}$ cells allowing them to develop in functional effector T cells.

\section{Conclusion}

Taken together, the presented data give a strong rationale to test re-directed FAP-specific $\mathrm{T}$ cells in patients with MPM since in vitro and in vivo functionality was clearly demonstrated and FAP expression is present in all subtypes of MPM. However, special caution is necessary in the selection of patients. Patients with chronic inflammatory diseases should be excluded when targeting FAP + tumors with FAP-specific re-directed T cells. Based on these data, we recommend the adoptive transfer of redirected $\mathrm{T}$ cells in a loco-regional fashion to minimize immediate systemic distribution and unexpected recognition of FAP in off-site tissues. As loco-regional therapy, adoptive transfer could be performed in body cavities like pleura or peritoneum or directly in the tumor tissue [45]. This approach could also lead to a reduction of the number of adoptively transferred cells resulting in small scale production of re-directed $\mathrm{T}$ cells with reduced costs and fewer technical hurdles for GMP production. Due to the expression pattern of FAP in malignant tissues FAP specific re-directed $\mathrm{T}$ cells have the potential to demonstrate anti-tumor effects besides MPM in a wide variety of different cancers.

\section{Consent}

This study was in accordance with Swiss laws and approved by the ethical committee of the Kanton Zurich (ref. nr. Stv.29-2009 and KEK No. 475).

\section{Additional file}

Additional file 1: Supplemental figures.

\section{Competing interests}

The authors declare that they have no competing interests.

\section{Authors' contributions}

PCS, SMJ, CR, UP designed the research plan. PCS, UP wrote the manuscript. PCS, $\mathrm{CH}, \mathrm{PG}, \mathrm{OMB}$ performed IHC, killing assays, ELISAs, animal experiments. PCS, UP analyzed data, created the figures, performed statistics. AS performed histology reports. AJ, AM, AS, RS, MvB provided vital reagents/materials/animals. All authors read and approved the final manuscript.

\section{Acknowledgements}

We would like to thank Sascha Kleber and Stephan Malzacher for excellent technical assistance. Furthermore, we thank Hinrich Abken and Markus Chmielewski (University of Cologne, Germany) for the pBullet plasmid. We are indebted to Martin Pruschy, Martina Zimmermann and Katrin Orlowski (University Hospital Zurich, Switzerland) for providing the pGL4.26 plasmid and excellent support with in vivo imaging. The here presented pre-clinical experiments for a phase I clinical study testing of FAP-re-directed T cells in MPM were partly planned and designed at the 12th joint ECCO-AACR-EORTCESMO Workshop 'Methods in Clinical Cancer Research', Waldhaus Flims, Switzerland, $19-25$ June 2010

\section{Author details}

${ }^{1}$ Department of Oncology, University Hospital Zurich, Rämistr. 100, 8091 Zürich, Switzerland. 'Laboratory of Molecular and Tumor Immunology, Earle A. Chiles Research Institute, Providence Cancer Center and Providence Portland Medical Center, 4805 NE Glisan St., Portland, OR 97213, USA. ${ }^{3}$ Institute of Surgical Pathology, University Hospital Zurich, Schmelzbergstr.12, 8091 Zurich, Switzerland. ${ }^{4}$ Center of Experimental Rheumatology, University Hospital Zurich, Gloriastr. 23, 8091 Zürich, Switzerland. ${ }^{5}$ Department of Immunology, University Hospital Zurich, Rämistr. 100, 8091 Zürich, Switzerland.

Received: 25 March 2013 Accepted: 29 July 2013

Published: 12 August 2013

\section{References}

1. Raja S, Murthy SC, Mason DP: Malignant pleural mesothelioma. Curr Oncol Rep 2011, 13:259-264.

2. Teta MJ, Mink PJ, Lau E, Sceurman BK, Foster ED: US mesothelioma patterns 1973-2002: indicators of change and insights into background rates. Eur J Cancer Prev 2008, 17:525-534.

3. Opitz I, Kestenholz P, Lardinois D, Muller M, Rousson V, Schneiter D, Stahel R, Weder W: Incidence and management of complications after neoadjuvant chemotherapy followed by extrapleural pneumonectomy for malignant pleural mesothelioma. Eur J Cardiothorac Surg 2006, 29:579-584.

4. Weder W, Opitz I, Stahel R: Multimodality strategies in malignant pleural mesothelioma. Semin Thorac Cardiovasc Surg 2009, 21:172-176.

5. Sugarbaker DJ, Garcia JP, Richards WG, Harpole DH Jr, Healy-Baldini E, DeCamp MM Jr, Mentzer SJ, Liptay MJ, Strauss GM, Swanson SJ: Extrapleural pneumonectomy in the multimodality therapy of malignant pleural mesothelioma. Results in 120 consecutive patients. Ann Surg 1996, 224:288-294. discussion 294-286.

6. Ertl HC, Zaia J, Rosenberg SA, June CH, Dotti G, Kahn J, Cooper LJ, Corrigan-Curay J, Strome SE: Considerations for the clinical application of chimeric antigen receptor T cells: observations from a recombinant DNA advisory committee symposium held June 15, 2010. Cancer Res 2011, 71:3175-3181.

7. Kershaw MH, Teng MW, Smyth MJ, Darcy PK: Supernatural T cells: genetic modification of T cells for cancer therapy. Nat Rev Immunol 2005, 5:928-940.

8. Porter $\mathrm{DL}$, Levine $\mathrm{BL}$, Kalos $\mathrm{M}$, Bagg $\mathrm{A}$, June $\mathrm{CH}$ : Chimeric antigen receptor-modified T cells in chronic lymphoid leukemia. N Engl J Med 2011, 365:725-733.

9. Kershaw MH, Westwood JA, Parker LL, Wang G, Eshhar Z, Mavroukakis SA, White DE, Wunderlich JR, Canevari S, Rogers-Freezer L, et al: A phase I study on adoptive immunotherapy using gene-modified $T$ cells for ovarian cancer. Clin Canc Res 2006, 12:6106-6115.

10. Louis CU, Savoldo B, Dotti G, Pule M, Yvon E, Myers GD, Rossig C, Russell HV, Diouf $O$, Liu E, et al: Antitumor activity and long-term fate of chimeric antigen receptor-positive T cells in patients with neuroblastoma. Blood 2011, 118:6050-6056.

11. Stewart-Jones G, Wadle A, Hombach A, Shenderov E, Held G, Fischer E, Kleber S, Nuber N, Stenner-Liewen F, Bauer S, et al: Rational development 
of high-affinity T-cell receptor-like antibodies. Proc Natl Acad Sci U S A 2009, 106:5784-5788.

12. Schuberth $P C$, Jakka G, Jensen SM, Wadle A, Gautschi F, Haley D, Haile S, Mischo A, Held G, Thiel M, et al: Effector memory and central memory NY-ESO-1-specific re-directed T cells for treatment of multiple myeloma. Gene Ther 2012, 20:386-395.

13. Garin-Chesa P, Old LJ, Rettig WJ: Cell surface glycoprotein of reactive stromal fibroblasts as a potential antibody target in human epithelial cancers. Proc Natl Acad Sci U S A 1990, 87:7235-7239.

14. Rettig WJ, Garin-Chesa P, Healey JH, Su SL, Ozer HL, Schwab M, Albino AP, Old $\mathrm{L}$ : Regulation and heteromeric structure of the fibroblast activation protein in normal and transformed cells of mesenchymal and neuroectodermal origin. Canc Res 1993, 53:3327-3335.

15. Park JE, Lenter MC, Zimmermann RN, Garin-Chesa P, Old LJ, Rettig WJ: Fibroblast activation protein, a dual specificity serine protease expressed in reactive human tumor stromal fibroblasts. J Biol Chem 1999, 274:36505-36512.

16. Dohi O, Ohtani H, Hatori M, Sato E, Hosaka M, Nagura H, Itoi E, Kokubun S: Histogenesis-specific expression of fibroblast activation protein and dipeptidylpeptidase-IV in human bone and soft tissue tumours. Histopathology 2009, 55:432-440.

17. Scanlan MJ, Raj BK, Calvo B, Garin-Chesa P, Sanz-Moncasi MP, Healey JH, Old L, Rettig WJ: Molecular cloning of fibroblast activation protein alpha, a member of the serine protease family selectively expressed in stromal fibroblasts of epithelial cancers. Proc Natl Acad Sci U S A 1994, 91:5657-5661.

18. Jacob M, Chang L, Pure E: Fibroblast activation protein in remodeling tissues. Curr Mol Med 2012, 12:1220-1243.

19. Kraman M, Bambrough PJ, Arnold JN, Roberts EW, Magiera L, Jones JO, Gopinathan A, Tuveson DA, Fearon DT: Suppression of antitumor immunity by stromal cells expressing fibroblast activation protein-alpha. Science 2010, 330:827-830.

20. Scott AM, Wiseman G, Welt S, Adjei A, Lee FT, Hopkins W, Divgi CR, Hanson LH, Mitchell P, Gansen DN, et al: A phase I dose-escalation study of sibrotuzumab in patients with advanced or metastatic fibroblast activation protein-positive cancer. Clin Canc Res 2003, 9:1639-1647

21. Hofheinz RD, al-Batran SE, Hartmann F, Hartung G, Jager D, Renner C, Tanswell P, Kunz U, Amelsberg A, Kuthan H, Stehle G: Stromal antigen targeting by a humanised monoclonal antibody: an early phase II trial of sibrotuzumab in patients with metastatic colorectal cancer. Onkologie 2003, 26:44-48.

22. Welt S, Divgi CR, Scott AM, Garin-Chesa P, Finn RD, Graham M, Carswell EA, Cohen A, Larson SM, Old LJ, et al: Antibody targeting in metastatic colon cancer: a phase I study of monoclonal antibody F19 against a cellsurface protein of reactive tumor stromal fibroblasts. J Clin Oncol 1994, 12:1193-1203.

23. Kofler DM, Chmielewski M, Rappl G, Hombach A, Riet T, Schmidt A, Hombach AA, Wendtner CM, Abken H: CD28 costimulation Impairs the efficacy of a redirected t-cell antitumor attack in the presence of regulatory $\mathrm{t}$ cells which can be overcome by preventing Lck activation. Mol Ther 2011, 19:760-767.

24. Willemsen RA, Ronteltap C, Chames P, Debets R, Bolhuis RL: T cell retargeting with $\mathrm{MHC}$ class I-restricted antibodies: the CD28 costimulatory domain enhances antigen-specific cytotoxicity and cytokine production. J Immunol 2005, 174:7853-7858.

25. Bauer S, Adrian N, Williamson B, Panousis C, Fadle N, Smerd J, Fettah I, Scott AM, Pfreundschuh M, Renner C: Targeted bioactivity of membrane-anchored TNF by an antibody-derived TNF fusion protein. J Immunol 2004, 172:3930-3939.

26. Held G, Matsuo M, Epel M, Gnjatic S, Ritter G, Lee SY, Tai TY, Cohen CJ, Old $L$, Pfreundschuh $M$, et al: Dissecting cytotoxic $T$ cell responses towards the NY-ESO-1 protein by peptide/MHC-specific antibody fragments. Eur J Immunol 2004, 34:2919-2929.

27. Ospelt C, Mertens JC, Jungel A, Brentano F, Maciejewska-Rodriguez H, Huber LC, Hemmatazad H, Wuest T, Knuth A, Gay RE, et al: Inhibition of fibroblast activation protein and dipeptidylpeptidase 4 increases cartilage invasion by rheumatoid arthritis synovial fibroblasts. Arthritis Rheum 2010, 62:1224-1235.

28. Payeli SK, Kollnberger S, Marroquin Belaunzaran O, Thiel M, McHugh K, Giles J, Shaw J, Kleber S, Ridley A, Wong-Baeza I, et al: Inhibiting HLA-B27 homodimerdriven immune cell inflammation in spondylarthritis. Arthritis Rheum 2012, 64:3139-3149.
29. Weijtens ME, Willemsen RA, van Krimpen BA, Bolhuis RL: Chimeric scFv/ gamma receptor-mediated T-cell lysis of tumor cells is coregulated by adhesion and accessory molecules. Int J Canc 1998, 77:181-187.

30. Hombach A, Hombach AA, Abken H: Adoptive immunotherapy with genetically engineered T cells: modification of the IgG1 Fc 'spacer' domain in the extracellular moiety of chimeric antigen receptors avoids 'off-target' activation and unintended initiation of an innate immune response. Gene Ther 2010, 17:1206-1213.

31. Petrausch U, Schuberth PC, Hagedorn C, Soltermann A, Tomaszek S, Stahel R, Weder W, Renner C: Re-directed T cells for the treatment of fibroblast activation protein (FAP)-positive malignant pleural mesothelioma (FAPME-1). BMC Canc 2012, 12:615.

32. Stahel RA, Felley-Bosco E, Opitz I, Weder W: Malignant pleural mesothelioma. Future Oncol 2009, 5:391-402.

33. Jakobsen JN, Sorensen JB: Review on clinical trials of targeted treatments in malignant mesothelioma. Canc Chemother Pharmacol 2011, 68:1-15.

34. Izzi V, Masuelli L, Tresoldi I, Foti C, Modesti A, Bei R: Immunity and malignant mesothelioma: from mesothelial cell damage to tumor development and immune response-based therapies. Canc Lett 2012, 322:18-34.

35. Gattinoni L, Lugli E, Ji Y, Pos Z, Paulos CM, Quigley MF, Almeida JR, Gostick E, Yu Z, Carpenito C, et al: A human memory T cell subset with stem cell-like properties. Nat Med 2011, 17:1290-1297.

36. Morgan RA, Yang JC, Kitano M, Dudley ME, Laurencot CM, Rosenberg SA Case report of a serious adverse event following the administration of $T$ cells transduced with a chimeric antigen receptor recognizing ERBB2. Mol Ther 2010, 18:843-851.

37. Bauer S, Jendro MC, Wadle A, Kleber S, Stenner F, Dinser R, Reich A, Faccin E, Godde S, Dinges $\mathrm{H}$, et al: Fibroblast activation protein is expressed by rheumatoid myofibroblast-like synoviocytes. Arthritis Res Ther 2006, 8:R171.

38. Brokopp CE, Richards P, Bauer S, Aikawa E, Graves K, Vogt P, Renner C, Luescher TF, Hoerstrup SP, Matter CM: Fibroblast activation protein is induced by inflammation and degrades collagen in vulnerable human atherosclerotic plaques. European Heart Journal 2010, 31:829-829.

39. Brokopp CE, Schoenauer R, Richards P, Bauer S, Lohmann C, Emmert MY, Weber B, Winnik S, Aikawa E, Graves K, et al: Fibroblast activation protein is induced by inflammation and degrades type I collagen in thin-cap fibroatheromata. Eur Heart J 2011, 32:2713-2722.

40. Friedmann-Morvinski D, Bendavid A, Waks T, Schindler D, Eshhar Z Redirected primary $T$ cells harboring a chimeric receptor require costimulation for their antigen-specific activation. Blood 2005, 105:3087-3093.

41. Krause A, Guo HF, Latouche JB, Tan C, Cheung NK, Sadelain M: Antigendependent CD28 signaling selectively enhances survival and proliferation in genetically modified activated human primary T lymphocytes. J Exp Med 1998, 188:619-626.

42. Cooper D, Bansal-Pakala P, Croft M: 4-1BB (CD137) controls the clonal expansion and survival of CD8 T cells in vivo but does not contribute to the development of cytotoxicity. Eur J Immunol 2002, 32:521-529.

43. Hacein-Bey-Abina S, Hauer J, Lim A, Picard C, Wang GP, Berry CC, Martinache C, Rieux-Laucat F, Latour S, Belohradsky BH, et al: Efficacy of gene therapy for X-linked severe combined immunodeficiency. $N$ Engl J Med 2010, 363:355-364.

44. Scholler J, Brady TL, Binder-Scholl G, Hwang WT, Plesa G, Hege KM, Vogel AN, Kalos M, Riley JL, Deeks SG, et al: Decade-long safety and function of retroviral-modified chimeric antigen receptor T cells. Sci Trans/ Med 2012, 4:132ra153.

45. Parente-Pereira AC, Burnet J, Ellison D, Foster J, Davies DM, van der Stegen S, Burbridge S, Chiapero-Stanke L, Wilkie S, Mather S, Maher J: Trafficking of CARengineered human $T$ cells following regional or systemic adoptive transfer in SCID beige mice. J Clin Immunol 2011, 31:710-718.

\section{doi:10.1186/1479-5876-11-187}

Cite this article as: Schuberth et al:: Treatment of malignant pleural mesothelioma by fibroblast activation protein-specific re-directed T cells. Journal of Translational Medicine 2013 11:187. 